\title{
Changes in presentation and outcomes in cardiac surgery patients aged 70 to 79 years versus patients 80 years or older
}

\author{
Aarne Jyrala $^{1 \#}$, Nicole M. Gatto ${ }^{2}$, Gregory L. Kay ${ }^{1}$ \\ ${ }^{1}$ Department of Cardiothoracic Surgery, Heart Institute at Good Samaritan Hospital, Los Angeles, USA \\ ${ }^{2}$ Department of Biostatistics, School of Public Health, University of Los Angeles, Los Angeles, USA \\ Email: "lathoracic@hotmail.com
}

Received 18 April 2012; revised 14 May 2012; accepted 12 June 2012

\section{ABSTRACT}

Background: To establish which variables between cardiac surgery pts aged 70 - 79 years and 80 years or over are individually different for age group status. Methods: Group 1, 70 - 79 years, $n=351$ and Group 2 , age 80 or over $n=94$. Demographics, operative and hospital outcomes were identified and EuroSCORE (ES) scores applied. Logistic regression uni- and multivariate analysis was used to detect pre- and postoperative variables which might be independently different between the Groups. Results: Difference ( $p<$ 0.05) was noted in (higher in Group 2) patients with CHF, NYHA class, atrial fibrillation, aortic valve disease, both ES algorithms. Group 2 pts had lower ejection fraction and less coronary artery disease. Group 1 had more pts with diabetes. Operative mortality was low $(1.7 \%$ total) with no difference between the Groups. Length of stay in the postoperative intensive care unit and total hospitalization was equal but Group 2 pts needed more often prolonged stay. Group 2 pts had more postoperative renal failure $(p=0.002)$ and were more often not discharged home $(p=0.03)$. Hospital mortality did not reach statistical significance (Group 1 18/5.2\%, Group 2 10/10.7\%, p = 0.06). Univariate analysis detected 12 pre- and postoperative variables which identified Group status. Multivariate analysis using univariate results detected only diabetes (for Group 1 status) and additive ES (for Group 2 status) to be independently different between the Groups. Conclusions: Elderly pts may be operated with low operative and hospital mortality. Only diabetes and additive ES (=comorbidities) were independently different between the Groups.

Keywords: Cardiac Surgery in Elderly; Differences;

*This work was supported by Elma Larsson Foundation, Los Angeles USA and Los Angeles Thoracic and Cardiovascular Foundation, Los Angeles USA.

${ }^{\#}$ Corresponding author.
Outcomes

\section{INTRODUCTION}

During the last several years ages of patients undergoing cardiac surgery have increased considerably and patients over 80 years are common in most cardiac surgery units.

Risk factors for elderly undergoing cardiac surgery are well documented [1-3] and several reports confirm good early and late results [1,4-6]. As we get older there are age-dependent structural and functional changes which affect the presentation characteristics and outcomes as well as changes in disease patterns [7]. Most reports compare groups of elderly pts to younger groups mostly undergoing one type of surgery (e.g. $>70$ years vs $<70$ years, $\mathrm{CABG}$ only surgery) but there are few reports available where two groups of elderly pts are compared undergoing mixed cardiac surgery procedures [8-10]. The aim of this study is to report changes in presentation details, risk scores by EuroSCORE (ES) $[11,12]$ and outcomes between pts aged $70-79$ (Group 1) with pts 80 years or older (Group 2). The results are used to evaluate which variables are independent predictors for Group status of the patients.

\section{MATERIAL AND METHODS}

1000 consecutive cardiac surgery patients between January 1999 to May 2000 were retrospectively studied and patients aged 70 years or older were identified and dichotomized into Groups by age: Group 1: age 70 - 79 years, Group 2: age 80 years or over.

Hospital records were reviewed for demographic characteristics, admitting diagnoses, findings from preoperative studies and hospital course. Follow-up all-cause mortality was achieved from Social Security Death Main Index [13] up to $10+$ years. All patients were retrospectively allocated risk scores by EuroSCORE) using the 
online calculator [14]. Preoperative risk scoring may be used not only for morbidity/mortality predictions but also for comparison of patient groups. ES was used because of its simplicity and reliability $[11,12]$. Logistic regression analysis is used to determine which variables are important in determine the Group status of pts.

Life expectancy of patients was achieved from Social Security Period Life Table [15] and Centers of Disease Control and Prevention [16].

The study was approved by hospital ethics committee and consent waived because pts were not contacted and calculations were made from a database without identifiers.

\section{STATISTICAL ANALYSIS}

Mean values of ES [additive (AES) and logistic (LES)] were calculated and categories were created to divide patients into low- (AES $\leq 6$; LES $\leq 25 \%)$ and high-risk groups (AES $>6$; LES $>25 \%$ ). Length of stay in the hospital (LOS) and intensive care unit (ICU) (both in days) were used in their continuous form $(<11$ days versus $>10$ days for hospital stay; 1 - 2 days versus $>2$ days for ICU stay). Additional variables were examined in their continuous form and categorized as follows: baseline serum creatinine $(>2.2 \mathrm{mg} / \mathrm{dL}, \leq 2.2 \mathrm{mg} / \mathrm{dL})$, left ventricle ejection fraction $(\leq 0.5,>0.5)$ and New York Heart Association (NYHA) class (I-II, III-IV). ES variables, operative characteristics, surgical outcomes and follow-up measures were summarized by groups of patients defined by age (Group 1: aged $70-79$ years, $\mathrm{n}=351$; Group 2: aged 80 or older, $\mathrm{n}=94)$. Variables were compared between groups of patients using simple parametric t-tests or chi-square tests, and a p-value $<0.05$ for the difference was regarded as statistically significant. Logistic regression methods were used to estimate odds ratios (ORs) and 95\% confidence intervals (95\% CIs) comparing patients aged 80 or older to those aged $70-79$ years. ORs expressed the probability that a given factor was more or less likely to be associated with older patients ( $\geq 80$ years) than younger patients ( 70 - 79 years). Univariate models were employed to calculate individual associations between patient groups and a given factor. Multivariate models were used to determine which univariate predictors were significantly associated with patient group status after taking into consideration the effect of other variables. Those variables that were associated with patient group status at $\mathrm{p}<0.05$ were considered independently different between groups.

All analyses used SAS version 9.2 (SAS Institute Inc., Cary, NC, USA).

\section{SURGICAL TECHNIQUE}

All pts were operated through standard median sternotomy. Pts operated on-pump the aortic inflow was into the ascending aorta or femoral artery as indicated. Venous drainage was accomplished with vacuum assist through single, double or femoral cannulation as indicated. Operations were performed in moderate hypothermia to $34^{\circ} \mathrm{C}$. Myocardial protection was accomplished with antegrade and retrograde cold whole blood cardioplegia, retrograde given continuously stopping only when it interfered with visualization and only for a maximum of 10 minutes at the time. Before release of cross-clamp $500 \mathrm{ml}$ of warm blood was given retrogradely.

Results. There were 445 patients aged 70 years or more. These patients were dichotomized into two groups by age: Group 1 pts aged 70 to 79 years $(n=351)$ and Group 2 pts aged 80 years or more $(n=94)$.

Preoperative patient characteristics are summarized in Table 1. There were statistically significant differences between the groups in the following demographic variables: Group 2 pts were older by definition, mean NYHA class was higher $(p=0.0003)$, mean EF was lower $(p=$ $0.04)$, there were less pts with diabetes and more pts with congestive heart failure $(p=0.007)$. There were more $p t s$ with coronary artery disease as the main diagnosis in Group $1(\mathrm{p}=0.01)$ and more pts with aortic valve disease in Group $2(\mathrm{p}=0.02)$. S-crea was similar but Group $2 \mathrm{pts}$ had significantly more atrial fibrillation $(\mathrm{AF}), \mathrm{p}=0.004$. Risk scores by both ES algorithms were significantly higher in Group 2 pts ( $p<0.0001$ for additive ES, AES and $p<0.0001$ for logistic ES, LES). Comparing single ES variables the only significant difference was in number of pts with other surgery than CABG only which was higher in Group $2(p=0.005)$. There were no statistically significant differences between other variables although Group 2 pts had higher numbers in most variables contributing to the higher total ES scores in Group 2 pts. Details are summarized in Table 2. Additive ES of $>6$ is regarded marking a high-risk pt. There were 226 (64.4\%) of these pts in Group 1 and 90 (95.7\%) in Group 2, p < 0.0001 . LES $>25 \%$ marks a very high-risk pt. There were $52(14.8 \%)$ of these in Group 1 and 36 (38.3\%) in Group 2, $\mathrm{p}<0.0001$ When the age factor from ES calculations was deleted AES was still significantly higher in Group 2 pts $(5.7 \pm 3.5$ vs $4.6 \pm 3.3), \mathrm{p}=0.005$ but not LES $(8.0 \% \pm$ $10.0 \%$ vs $6.3 \% \pm 10.0 \%) \mathrm{p}=0.14$. Leaving age out from ES calculations reduced significantly numbers of highrisk pts (AES > 6): 72 (20.5\%) in Group 1 and 32 (34.0\%) in Group 2, p = 0.008; and very high-risk pts (LES > 25\%): $17(4.8 \%)$ in Group 1 and $9(9.6 \%)$ in Group 2, $\mathrm{p}=$ 0.09 . Both ES algorithms overestimated operative and hospital/30 day mortality. Leaving the age factor out from ES calculations both algorithms predicted hospital/30 day mortality quite well. Group 1: predicted by AES $4.4(6 \%$ $8 \%$ ), observed $5.2 \%$ and by LES: $6.5 \%$ predicted, $5.2 \%$ observed. Group 2: predicted by AES 5.5 (7\% - 10\%), observed $10.7 \%$ and with LES: predicted $8.6 \%$, observed $10.7 \%$. Details of surgery were similar between the groups 
Table 1. Demographics.

\begin{tabular}{|c|c|c|c|}
\hline Variable & $\begin{array}{l}\text { Group } 1, \mathrm{n}=351 \\
\mathrm{n}(\%) / \text { mean } \pm \mathrm{SD}\end{array}$ & $\mathrm{p}$-value ${ }^{1}$ & $\begin{array}{l}\text { Group } 2, \mathrm{n}=94 \\
\mathrm{n}(\%) / \text { mean } \pm \mathrm{SD}\end{array}$ \\
\hline Age/Years & $74.3 \pm 2.7$ & $<0.0001$ & $82.8 \pm 2.5$ \\
\hline Females & $121(34.5)$ & 0.21 & $39(41.5)$ \\
\hline BMI & $26.9 \pm 4.8$ & 0.08 & $26.0 \pm 4.4$ \\
\hline NYHA & $2.7 \pm 0.7$ & 0.0003 & $3.0 \pm 0.8$ \\
\hline NYHA III-IV pts & $193(56.0)$ & 0.005 & $67(71.3)$ \\
\hline $\mathrm{EF}$ & $0.5 \pm 0.15$ & 0.04 & $0.4 \pm 0.15$ \\
\hline $\mathrm{EF}<0.5$ & $189(53.9)$ & 0.42 & $55(58.5)$ \\
\hline $\mathrm{AF}$ & $34(9.7)$ & 0.004 & $20(21.3)$ \\
\hline s-crea, mg/dl & $1.2 \pm 0.9$ & 0.69 & $1.3 \pm 0.6$ \\
\hline $\mathrm{s}-\mathrm{crea}>2.2 \mathrm{mg} / \mathrm{dl}$ & $22(6.4)$ & 0.83 & $7(7.4)$ \\
\hline Diabetes & $140(39.9)$ & 0.03 & $26(27.7)$ \\
\hline $\mathrm{CHF}$ & $115(32.8)$ & 0.0007 & $49(52.1)$ \\
\hline Hypothyroid pts & $43(12.3)$ & 0.59 & $9(9.6)$ \\
\hline Emergency op & $29(8.3)$ & 0.23 & $12(12.8)$ \\
\hline \multicolumn{4}{|l|}{ Main op diagnosis } \\
\hline CAD & $275(78.4)$ & 0.01 & $61(64.9)$ \\
\hline $\mathrm{AS} / \mathrm{AI}$ & $53(15.0)$ & 0.02 & $23(22.5)$ \\
\hline MR/MS & $9(5.4)$ & 0.46 & $7(7.5)$ \\
\hline Other & $4(1.1)$ & 0.17 & $3(3.2)$ \\
\hline AES & $8.1 \pm 3.4$ & $<0.0001$ & $11.0 \pm 3.6$ \\
\hline $\mathrm{AES}>6$ & $226(64.4)$ & $<0.0001$ & $90(95.7)$ \\
\hline LES & $14.3 \pm 16.1$ & $<0.0001$ & $26.5 \pm 21.2$ \\
\hline LES $>25 \%$ & $52(14.8)$ & $<0.0001$ & $36(38.3)$ \\
\hline
\end{tabular}

BMI: body mass index, $\mathrm{kg} / \mathrm{m}^{2}$; NYHA: New York Heart Association functional classification; EF: left ventricular ejection fraction, normal > 0.5; AF: atrial fibrillation; s-crea: swerum creatinine content; CHF: congestive heart failure; CAD: coronary artery disease; AS/AI: aortic valve stenosis/insufficiency; MR/MS: mitral valve regurgitation/stenosis; AES: additive EuroSCORE; LES: logistic EuroSCORE, \%; ${ }^{1}$-value from two sample independent t-test or chi-square test; or when cell counts were small, Fisher's exact test.

Table 2. EuroSCORE variables.

\begin{tabular}{|c|c|c|c|}
\hline Variable & Group $1(\mathrm{n} / \%)$ & p-value & Group $2(n / \%)$ \\
\hline Age 60 or over & $351(100)$ & 1 & $94(100)$ \\
\hline Females & $121(34.5)$ & 0.21 & $39(41.5)$ \\
\hline Chronic pulmonary dis. & $58(16.5)$ & 0.91 & $16(17.0)$ \\
\hline Periph. arteriopathies & $91(25.9)$ & 0.25 & $30(1.9)$ \\
\hline Neurological dysfunction & $25(7.1)$ & 0.44 & $9(9.6)$ \\
\hline Previous cardiac surgery & $42(11.9)$ & 0.51 & $9(9.6)$ \\
\hline $\mathrm{s}-\mathrm{crea}>200 \mu \mathrm{mol} / 1$ & $26(7.4)$ & 0.73 & $6(6.4)$ \\
\hline Endocarditis & $1(0.3)$ & 0.38 & $1(1.1)$ \\
\hline Critical preop. condition & $18(5.1)$ & 0.23 & $8(8.5)$ \\
\hline Unstable angina & $52(14.8)$ & 0.31 & $18(19.1)$ \\
\hline $\mathrm{EF}<0.3$ & $49(14.0)$ & 0.63 & $15(16.0)$ \\
\hline EF $0.3-0.5$ & $137(39.0)$ & 0.72 & $40(42.6)$ \\
\hline Emergency operation & $29(8.3)$ & 0.20 & $12(12.8)$ \\
\hline AMI within 90 days & $84(23.9)$ & 0.46 & $26(27.7)$ \\
\hline $\mathrm{PAP}>60 \mathrm{mmHg}$ & $11(3.1)$ & 0.53 & $4(4.3)$ \\
\hline Other than CABG only & 97 (27.6) & 0.001 & $43(45.7)$ \\
\hline Post AMI VSD & $3(0.9)$ & 0.99 & 0 \\
\hline
\end{tabular}

s-crea: serum creatinine concentration; EF: left ventricular ejection fraction; AMI: acute myocardial infarction; PAP: systolic pulmonary artery pressure; CABG: coronary artery bypassgrafting; VSD: ventricular septal rupture. 
besides number of CABG only surgery in Group $1, \mathrm{p}=$ 0.005 and more pts with procedures on aortic valve in Group 2, $\mathrm{p}=0.03$. Details in Table 3. Operative mortality was low $(6 / 1.7 \%$ in Group 1 and $1 / 1.1 \%, p=1.00)$ in both groups, cardiopulmonary bypass times, aortic crossclamp times and need for IABP support postoperatively did not differ between the groups. All operative mortality pts had very high ES scores, mean AES $11.9 \pm 53$ and all pts had AES $>6$, mean LES $34.9 \% \pm 30.7 \%$ and 4 pts with LES > $25 \%$. All pts were in NYHA III-IV and 3 pts were operated as emergency. Hospital/30 day mortality was slightly higher in Group 2: 18/5.2\% in Group 1 and 10/10.7\% in Group 2, $\mathrm{p}=0.06$. AES for Group 1 hospital deaths was $11.5 \pm 4.36$ and for Group $212.2 \pm 4.24, \mathrm{p}=0.68$.

LES for Group 1 hospital deaths was $31.6 \% \pm 27.2 \%$ and for Group $234.1 \% \pm 21.07 \%, \mathrm{p}=0.82$. All pts were high-risk pts (AES $>6$ in both Groups). There were 8 (44.4\%) of very high-risk pts (LES $>25 \%$ ) in Group 1 and $6(60.0 \%)$ in Group $2, p=0.69$. There were no statistically significant differences in pts in NYHA class III-IV (all pts), number of emergency operations, $p=0.9$, pts with diabetes, $\mathrm{p}=0.26$, pts on dialysis, $\mathrm{p}=0.37$, preop s-crea, $\mathrm{p}=0.38$, pts with CHF, $\mathrm{p}=0.69$, pts with $\mathrm{EF}<0.3, \mathrm{p}=$ 0.37 or in the number of pts who needed IABP support, $\mathrm{p}$ $=0.08$.

Mean ICU for Group 1 was $2.63 \pm 5.93$ days, range 0 60 and median 1 day. For Group 2 it was $3.24 \pm 5.01$ days, range $0-25$ and median 1 day, $\mathrm{p}=0.36$.

There were more patients in Group 2 who had ICU $>2$ days $(24 / 25.81 \%$ vs $48 / 13.91 \%), p=0.01$.

Mean LOS for Group 1 patients was $8.40 \pm 6.43$ days, range 0 - 60 and median 6. For Group 2 it was $9.51 \pm 6.47$ days, range 0 - 44 days and median $7, p=0.11$. The need for prolonged hospitalization was similar between the Groups $(p=0.13)$. Occurrence of postoperative stroke (CVA) was similar between the Groups, $p=0.7$. Occurrence of postoperative renal failure (AKI) was higher in Group 2 pts $(\mathrm{p}=0.002)$ despite similar preoperative kidney status by s-crea. There were more postoperative AF in Group 1 calculated from pts with normal sinus rhythm preoperatively but the difference did not reach statistical significance $(\mathrm{p}=0.09)$.

Need for continued hospitalization or rehabilitation was considerably higher in Group 2 pts where 21/24.42\% pts were discharged to another institute, $\mathrm{p}=0.03$. Hospital outcomes are summarized in Table 4. Total follow-up time for Group 1 was 32460 months, mean $99.3 \pm 45.8$ months, median 114 months and range 1 to 150 months. For Group 2 total follow-up was 5956 months, mean 71.8 \pm 46.3 months, median 73 months and range $1-140$ months. At the closure of follow-up 132 pts (37.6\%) in Group 1 were alive and 11 pts (13.3\%) in Group 2, p < 0.0001 , all with a follow-up time of $10+$ years. Details are summarized in Table 5. Ninety two pts (28.1\%) exceeded their life expectancy at the closure of follow-up; 66 $(18.9 \%)$ in Group 1 (mean age $85.1 \pm 2.6$ years) and 26 (32.1\%) in Group 2, $\mathrm{p}=0.06$ (mean age $93.6 \pm 2.1$ years). Most variables by univariate analysis determined Group status but multivariate analysis revealed that only diabetes (for Group 1) and additive ES (for Group 2) were independent determinants of Group status. None of the operative and postoperative variables were independent determinants of Group status. OR for ages and follow-up mortality was not calculated. Results are summarized in Table 6. Comments. Cardiac surgery can be performed with low operative and hospital mortality on elderly

Table 3. Operative details.

\begin{tabular}{|c|c|c|c|}
\hline Variable & Group $1 \mathrm{~m} \pm \mathrm{SD} / \mathrm{n}(\%)$ & p-value & Group $2 \mathrm{~m} \pm \mathrm{SD} / \mathrm{n}(\%)$ \\
\hline \multicolumn{4}{|l|}{ Performed procedures } \\
\hline CABG only & $256(72.9)$ & 0.005 & $54(57.5)$ \\
\hline $\mathrm{CABG}+\mathrm{AVR}$ & $33(9.4)$ & 0.25 & $13(13.8)$ \\
\hline $\mathrm{CABG}+\mathrm{MVR}$ & $10(2.9)$ & 0.34 & $3(3.2)$ \\
\hline CABG + 2 VALVES & $1(0.3)$ & 0.39 & $1(1.1)$ \\
\hline AVR & $23(6.6)$ & 0.03 & $13(13.8)$ \\
\hline MVR & $7(2.0)$ & 0.45 & $3(3.2)$ \\
\hline DOUBLE VALVE & $5(1.4)$ & 0.61 & $1(1.1)$ \\
\hline OTHER & $10(2.9)$ & 0.99 & $3(3.2)$ \\
\hline TOTAL VALVES & $79(22.5)$ & 0.89 & $22(23.4)$ \\
\hline CPB & $116.2 \pm 47.7$ & 0.88 & $115.3 \pm 50.0$ \\
\hline X-CLAMP & $92.9 \pm 36.8$ & 0.71 & $91.2 \pm 38.3$ \\
\hline OPERATIVE MORTALITY & $6(1.7)$ & 0.36 & $1(1.1)$ \\
\hline IABP SUPPORT & $30(8.5)$ & 0.53 & $6(6.5)$ \\
\hline
\end{tabular}

CABG: coronary artery bypass grafting; AVR: aortic valve repair or replacement; MVR: mitral valve repair or replacement; CPB: cardiopulmonary bypass time, minutes; X-CLAMP: aortic cross-clamp time, minutes; IABP: intra-aortic balloon pulsation device. 
Table 4. Hospital outcomes.

\begin{tabular}{|c|c|c|c|}
\hline Variable & Group $1 \mathrm{~m} \pm \mathrm{SD} / \mathrm{n}(\%)$ & $\mathrm{p}$ & Group $2 \mathrm{~m} \pm \mathrm{SD} / \mathrm{n}(\%)$ \\
\hline Hospital/30 day mortality & $18(5.2)$ & 0.06 & $10(10.7)$ \\
\hline ICU & $2.6 \pm 5.9$ & 0.30 & $3.2 \pm 5.0$ \\
\hline ICU $>2$ days & $48(13.7)$ & 0.008 & $24(25.5)$ \\
\hline LOS & $8.3 \pm 6.5$ & 0.10 & $9.5 \pm 6.5$ \\
\hline LOS $>10$ days & $68(19.4)$ & 0.03 & $25(26.6)$ \\
\hline CVA & $12(3.4)$ & 0.70 & $4(4.3)$ \\
\hline POSTOP AKI $^{1}$ & $5(1.4)$ & 0.002 & $8(8.5)$ \\
\hline POSTOP AF ${ }^{2}$ & $38(10.8)$ & 0.09 & $5(5.3)$ \\
\hline DISCH TO INSTITUTE & $46(13.1)$ & 0.03 & $21(22.3)$ \\
\hline
\end{tabular}

ICU: days in the postoperative intensive care unit; LOS: length of hospitalization; CVA: cerebrovascular accident, stroke; AKI: postoperative acute kidney injury, increase of s-crea $>2.2 \mathrm{~g} / \mathrm{dl}$ with or without de novo dialysis in pts with preoperative s-crea $<2.2 \mathrm{mg} / \mathrm{dl}$; AF: atrial fibrillation in pts with preoperative sinus rhythm. ${ }^{1}$ Calculated from pts with s-crea $<2.25 \mathrm{mg} / \mathrm{dl}$ preoperatively, ${ }^{2}$ calculated from pts in normal sinus rhythm preoperatively.

Table 5. Follow-up.

\begin{tabular}{|c|c|c|c|}
\hline & Group $1 \mathrm{~m} \pm \mathrm{SD} / \mathrm{n}(\%)$ & $\mathrm{p}$ & Group $2 \mathrm{~m} \pm \mathrm{SD} / \mathrm{n}(\%)$ \\
\hline Mean follow-up, months & $98.6 \pm 46.1$ & $<0.0001$ & $63.4 \pm 49.3$ \\
\hline Range, months & $1-150$ & $1-140$ & \\
\hline Total f-u, months & & 31589 & 5956 \\
\hline Follow-up mortality & $195(59.6)$ & $<0.0001$ & $72(86.7)$ \\
\hline $\mathrm{F}-\mathrm{u}$ for pts alive, months ${ }^{1}$ & $140.2 \pm 6.4$ & 0.06 & $131.1 \pm 14.3$ \\
\hline F-u for pts expired, months & $72.1 \pm 40.6$ & 0.07 & $61.7 \pm 42.1$ \\
\hline Age at the end of $\mathrm{f}-\mathrm{u}^{1}$ & $85.1 \pm 2.6$ & $<0.0001$ & $93.5 \pm 2.1$ \\
\hline
\end{tabular}

${ }^{1}$ From pts alive at the end of f-u: Group $1 \mathrm{n}=127$, Group $2 \mathrm{n}=11$.

Table 6. Logistic regression analyses comparing variables of Group 2 to Group 1.

\begin{tabular}{lcc}
\hline Variable & Univariate OR $(95 \%$ CI $)$ & Multivariate OR (95\% CI) \\
\hline LVEF & $0.21(0.05-0.92)$ & $0.54(0.10-3.05)$ \\
Diabetes & $0.58(0.35-0.95)$ & $\mathbf{0 . 4 9}(\mathbf{0 . 2 8}-\mathbf{0 . 8 6})$ \\
CHF & $2.24(1.41-3.55)$ & $1.27(0.69-2.37)$ \\
Preop.AF & $2.20(1.27-3.08)$ & $1.18(0.56-2.12)$ \\
NYHA & $1.74(1.28-2.37)$ & $0.83(0.52-1.31)$ \\
CAD & $1.0(\mathrm{ref})$ & $1.0(\mathrm{ref})$ \\
AS/AI & $1.96(1.12-3.43)$ & $1.57(0.73-3.37)$ \\
MR/MS & $1.66(0.67-4.13)$ & $1.47(0.49-4.40)$ \\
Other & $3.38(0.74-15.50)$ & $1.79(0.32-9.97)$ \\
Additive EuroSCORE & $1.24(1.16-1.32)$ & $\mathbf{1 . 2 3}(\mathbf{1 . 1 2}-\mathbf{1 . 3 6 )}$ \\
Logistic EuroSCORE & $1.00(1.00-1.02)$ & - \\
Other than CABG only & $2.21(1.38-3.53)$ & $1.02(0.52-2.00)$ \\
ICU $>2$ days vs $<2$ days & $2.16(1.24-3.78)$ & $0.87(0.40-1.89)$ \\
LOS $>10$ days vs $<10$ days & $2.32(1.34-4.02)$ & $1.64(0.89-3.05)$ \\
Postoperative AF & $0.46(0.18-1.21)$ & - \\
Postoperative RF & $6.41(2.05-20.10)$ & $3.80(0.96-14.99)$ \\
Discharge to institute & $1.91(1.07-3.39)$ & $1.01(0.49-2.10)$ \\
Hospital mortality & $2.09(1.00-4.37)$ & $1.01(0.39-2.64)$ \\
\hline
\end{tabular}

LVEF: left ventricle ejection fraction; CHF: congestive heart failure; NYHA: New York Heart Association functional classification; CAD: coronary artery disease; AS/AI: aortic valve stenosis/insufficiency; MR/MS: mitral valve regurgitation/stenosis; CABG: coronary artery bypass graft; ICU: stay in postoperative intensive care unit; LOS: length of hospitalization. 
patients and acceptable outcomes may be expected [17, 18]. Engoren et al. [8] compared 103 octogerians to 103 septuagerians who underwent mixed cardiac surgery procedures. They observed more preoperative CVA's in octogerians which was not observed in our series $(p=0.44)$ and less preoperative renal dysfunction (similar in our series, $p=0.83$ ). The outcomes were quite similar to our series and they concluded that cardiac surgery can be performed in the elderly with good hospital and late functional results but with higher hospital costs. There are several statistically significant differences in patient demographic variables between Group 1 and 2 pts which are quite similar with other reports [19].

We have used ES for comparison of Groups rather than for mortality predictions as ES was designed for. The total ES scores were higher in Group 2 with very significant difference although among individual scores only other surgery than CABG only had a significant difference. Leaving the age factor out from calculations AES was higher in Group $2 p t s(p=0.005)$ but LES not $(p=0.14)$ underscoring the great impact of age in ES calculations in elderly pts. In a recent report from Frilling et al. [3] compared three different scores (STS, EuroSCORE and Ambler) for operative mortality in elderly pts. All scores overestimated operative mortality and they concluded that surgical risk scores for risk assessment and treatment decisions should be reevaluated. Leaving the age factor off the calculations may be a way to get more reliable calculations. Operative details were very similar between the Groups except in numbers of CABG and AVR procedures. Operative mortality in both Groups was very low and equal (total 7 of $445,1.6 \%$ ) which has not always been observed [20]. Hospital/30 day mortality was slightly higher in octogerians $(10.8 \%$ vs $5.2 \%, p=0.06)$ [21]. Risk adjusted hospital/30 day mortality was similar with no difference in AES or LES scores which were very high (AES $11.4 \pm 4.4$ vs $12.6 \pm 4.1, \mathrm{p}=0.48$ and LES $31.5 \pm$ 28.0 vs $36.3 \pm 26.4, p=0.66$ ). ICU and LOS were similar but Group 2 pts needed longer ICU and LOS with statistically significant difference against Group $1 \mathrm{pts}$, which is in concert with other relevant reports. There were no differences between postoperative occurrence of CVA's and $\mathrm{AF}$ despite high incidence of preoperative AF in Group 2 pts. The occurrence of renal failure was higher in Group 2 pts $(p=0.002)$ despite similar renal status by $s$-crea preoperatively and has been observed earlier [10]. Discharge home rate was lower in Group $2 \mathrm{pts}, \mathrm{p}=0.003$ which has been demonstrated by Bardacki et al. [22] although in this report $52.4 \%$ of octogerians were discharged home but is our series it was $77.7 \%$. Follow-up mortality was higher in Group 2 pts which is related to the age difference and differences in comorbidities but parallels the mortality of general population of same age [19]. Many pts in both Groups exceeded their life expectancy as also demonstrated by Collins et al. [5]. Univariate analysis was used to determine which individual variables were associated to Group status (Group 2 vs 1 ) and by this to outcomes. There were several variables associated with Group status in demographic variables $(\mathrm{n}=7)$, in operative $(n=1)$ and hospital outcomes $(n=4)$. Multivariate analysis of different variables from univariate analysis revealed that only diabetes (for Group 1 status) and AES (for Group 2 status) were independently and significantly associated with Group status Drawbacks. This is a retrospective observational study from a single institution with rather few numbers of pts.

\section{CONCLUSION}

Pts with advanced age may undergo cardiac surgery with low operative and hospital mortality. Only diabetes (for Group 1) and AES (for Group 2) are independent predictors for Group status. Changes in presentation characteristics and early outcomes do not justify declining needed cardiac surgery by advanced age only. The postoperative and early outcomes did not show any differences by multivariate analysis, so one may expect good early results in pts 80 years or over compared to pts 70 79 years old when good clinical judgment with risk assessment is used.

\section{REFERENCES}

[1] Collart, F., Feier, H., Kerbaul, F., et al. (2005) Valvular surgery in octogerians: Operative risk factors, evaluation of uroscore and long term results. European Journal Cardio-Thoracic Surgery, 27, 276-280.

doi:10.1016/j.ejcts.2004.10.041

[2] Deiwick, M., Tandler, R., Mollhoff, T., et al. (1997) Heart surgery in patients aged eighty years and above: Determinants of morbidity and mortality. The Thoracic and Cardiovascular Surgeon, 3, 119-126. doi:10.1055/s-2007-1013702

[3] Frilling, B., Von Renten-Kruse, W. and Rieb, F.C. (2010) Evaluation of operative risk in elderly patients undergoing aortic valve replacement: The predictive value of operative risk scores. Cardiology, 116, 213-218. doi:10.1159/000319703

[4] Collins, S.M., Brorsson, B., Svenmarker, S., Kling, P.A. and Aberg, T. (2002) Medium-term survival and quality of life of Swedish octogerians after open heart surgery. European Journal Cardio-Thoracic Surgery, 22, 794-801. doi:10.1016/S1010-7940(02)00330-5

[5] Fruitman, D.S., MacDougall, C.E. and Ross, D.B. (1999) Cardiac surgery in octogerians: Can elderly patients benefit? Quality of life after cardiac surgery. Annals of Thoracic Surgery, 68, 2129-2135. doi:10.1016/S0003-4975(99)00818-8

[6] Khan, J.H., Magnetti, S., Davis, E. and Zhand, J. (2000) Late outcomes of open heart surgery in patients 70 years 
or older. Annals of Thoracic Surgery, 69, 165-170. doi:10.1016/S0003-4975(99)01185-6

[7] Mortasawi, A., Arnrich, B., Rosendahl, U., et al. (2002) Is age an independent determinant of mortality as suggested by EuroSCORE? BMC Surgery, 2, 8-14. doi:10.1186/1471-2482-2-8

[8] Engoren, M., Arslanian-Engorren, C., Steckel, D., Nethardt, J. and Fenn-Buderer, N. (2002) Cost, outcome and functional status in octogerians and septuagerians after cardiac surgery. Chest, 122, 1309-1315. doi:10.1378/chest.122.4.1309

[9] Goyat, S., Henry, M. and Mohajeri, M. (2005) Outcome and quality of life after cardiac surgery in octogerians. ANZ Journal of Surgery, 75, 429-435. doi:10.1111/j.1445-2197.2005.03390.x

[10] Alexander, K.P., Anstrom, K.J., Muhlbaier, L.H., et al. (2000) Outcomes of cardiac surgery in patients age over 80 years: Results from the national cardiovascular network. Journal of the American College of Cardiology, 35, 731-738. doi:10.1016/S0735-1097(99)00606-3

[11] Nashef, S.A., Roques, F., Michel, P., Gauducheau, E., Lemeshow, S. and Salamon, R. (1999) European system for cardiac operative risk evaluation (EuroSCORE). European Journal Cardio-Thoracic Surgery, 16, 9-13. doi:10.1016/S1010-7940(99)00134-7

[12] Roques, F., Michel, P., Goldstone, A.R. and Nashef, S.A. (2003) The logistic EuroSCORE. European Heart Journal, 24, 882-883. doi:10.1016/S0195-668X(02)00799-6

[13] Social Security Main Death index. http://www.ssdmf.com

[14] EuroSCORE calculators. http://www.euroscore.org
[15] Social Security Period Life Table. http://www.ssa.gov/OACT/STATS/table4c6htms

[16] Centers of Disease Control and Prevention http://www.cdc.gov/nchs/fastats/lifexpec.htm\#

[17] Ghanta, R.K., Shekar, P.S., McGurk, S., Rosborough, D.M. and Aranki, S.F. (2011) Long-term survival and quality of life justify cardiac surgery in the very elderly patient. Annals of Thoracic Surgery, 92, 851-857. doi:10.1016/j.athoracsur.2011.04.083

[18] Zingone, B., Gatti, G., Rauber, E., et al. (2009) Early and late outcomes of cardiac surgery in octogerians. Annals of Thoracic Surgery, 87, 71-78. doi:10.1016/j.athoracsur.2008.10.011

[19] Nissinen, J., Wistbacka, J.-O., Loponen, P., et al. (2010) Coronary artery surgery in octogerians: Long-term outcome can be better than expected. Annals of Thoracic Surgery, 89, 1119-1124. doi:10.1016/j.athoracsur.2009.12.063

[20] Avery II, G.J., Ley, S.J., Hill, J.D., Hershon, J.J. and Dick, S.E. (2001) Cardiac surgery in the octogerian: Evaluation of risk, cost and outcome. Annals of Thoracic Surgery, 71, 591-596. doi:10.1016/S0003-4975(00)02163-9

[21] Yamane, K., Hirose, H., Youdelman, B.A., Bogar, L.J. and Diehl, J.T. (2011) Conventional aortic valve replacement for elderly patients in the current era. Circulation Journal, 5, 2692-2698. doi:10.1253/circj.CJ-11-0541

[22] Bardakci, H., Cheema, F.H., Topkara, V.K., et al. (2007) Discharge to home rates are significantly lower for octogerians undergoing coronary artery bypass graft surgery. Annals of Thoracic Surgery, 83, 483-489. doi:10.1016/j.athoracsur.2006.09.047 